\title{
Study on the Law of Diffusion of Sudden Pollutants in Subway Ventilation Shaft
}

\author{
Xinyi Lu, Yan Wu, Jingwei Wu and Jianbin Zang
}

\begin{abstract}
The underground subway stations have become the targets of terrorism due to the features of staff-intensive and poor ventilation. In the present study, the dynamic mesh model was used to predict the dynamic change of the flow field in the tunnel induced by the train motion. The DPM model was employed to simulate the interaction between the continuous phase of the air and the discrete phase of pollution particles. Accordingly, the dispersion of sudden pollutants released in the ventilation shaft was investigated. The results show that the submicron particles have a good following performance with the air. The dispersion characteristics of the particles highly depend on the unsteady flow field in the tunnel, which is significantly affected by the piston effect induced by the train motion. It can be concluded that particle diffusion experiences three stages: vertical forward and reverse diffusion in the wind shaft, vertical positive diffusion in the wind shaft, and longitudinal stable diffusion in the interval tunnel. It hopes that the study can provide guides for future biochemical protection in the subway system.
\end{abstract}

Keywords Subway system $\cdot$ Discrete phase model $\cdot$ Diffusion law

\footnotetext{
X. $\mathrm{Lu} \cdot \mathrm{Y} . \mathrm{Wu} \cdot \mathrm{J} . \mathrm{Wu} \cdot \mathrm{J}$. Zang $(\bowtie)$

School of Mechanical Engineering, Tongji University, Shanghai 201804, China

e-mail: 98798@tongji.edu.cn

X. Lu

e-mail: 15800982971@163.com

$\mathrm{Y} . \mathrm{Wu}$

e-mail: yan.wu@tongji.edu.cn

J. Wu

e-mail: 18721515992@163.com
} 


\section{Instruction}

Now, terrorists are increasingly rampant and the means of attack are becoming more diverse. Large-scale public buildings, where people spend the longest time, have the highest density of personnel. Sextro et al. [1] simulated the transmission process of the terrorist attack by mail anthrax bacillus in the building; Li et al. [2], using multi-zone airflow model, found that natural ventilation would help SARS virus spread in the building. In the sudden pollution of the ventilation system, Hao et al. [3] analyzed the harm of biochemical attacks in various scenarios and emphasized the possibility and destructiveness of the air-conditioning ventilation system to become the propagating power of biochemical pollution.

In this paper, CFD simulation method is used to reproduce the airflow field caused by piston effect in tunnel, and discrete phase model (DPM model) is used to simulate the propagation and diffusion of pollutant particles and airflow under the coupling action, so as to analyze the diffusion law of sudden pollutants in ventilation shaft.

\section{Method Validation}

The simulation study in this paper uses two complex models: the dynamic mesh model and the DPM model. This paper verifies the two models separately.

\subsection{Dynamic Mesh Model Verification}

In this paper, numerical simulation is carried out by establishing the same model as the literature [4]. The train runs at an acceleration of $1 \mathrm{~m} / \mathrm{s}^{2}$. When the train runs at a speed of $3 \mathrm{~m} / \mathrm{s}$, it runs at a constant speed of $8 \mathrm{~s}$. Finally, the train runs to stop at a deceleration of $1 \mathrm{~m} / \mathrm{s}^{2}$.

The model is divided into structured grids. The motion state is given to the whole fluid domain and the wall, and the tunnel surface is set as a non-slip boundary condition. The pressure inlet and the pressure outlet are used at the tunnel entrance and the tunnel exit respectively, and the calculation time step is set to $0.1 \mathrm{~s}$.

Dimensionless $u / u_{\max }$ is defined, where $\mathrm{u}$ is the wind speed, $0.5 \mathrm{~m}$ from the tunnel entrance, and $u_{\max }$ is the maximum speed of the train. Figure 1 is a comparison of the simulation results with the experimental results of the literature. The simulation results are in good agreement with the experimental results. Therefore, it can be explained that the CFD dynamic mesh technology can well simulate the natural ventilation of the subway tunnel under train movement. 


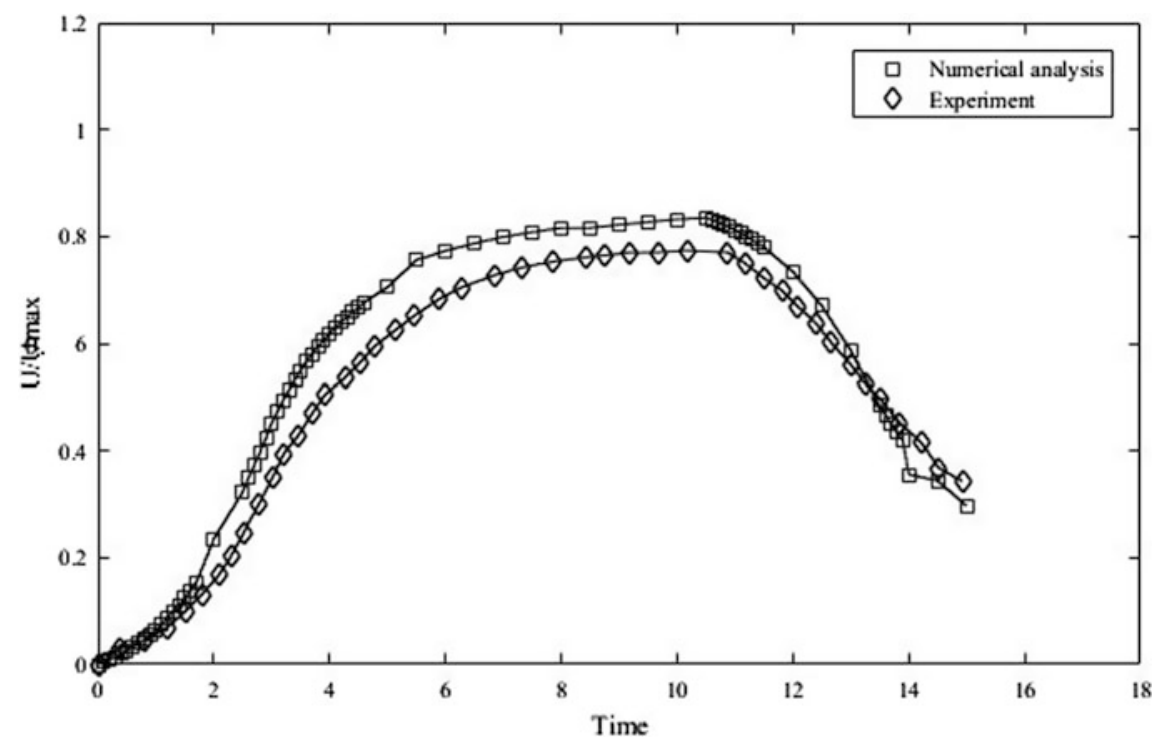

Fig. 1 Comparison of simulation and experimental data

\subsection{DPM Model Verification}

In the DPM model verification, this paper selects the three-dimensional full-scale room model in the literature [5] to simulate the change of particle concentration in two rooms. Figure 2 is the model used in the simulation.

At the initial time, the particles are evenly distributed in zone-1 space, and the density of the particles is $865 \mathrm{~kg} / \mathrm{m}^{3}$. In order to achieve uniform distribution of particles, 800 points were uniformly taken in zone-1 to synthesize a parcel as a source of emission.

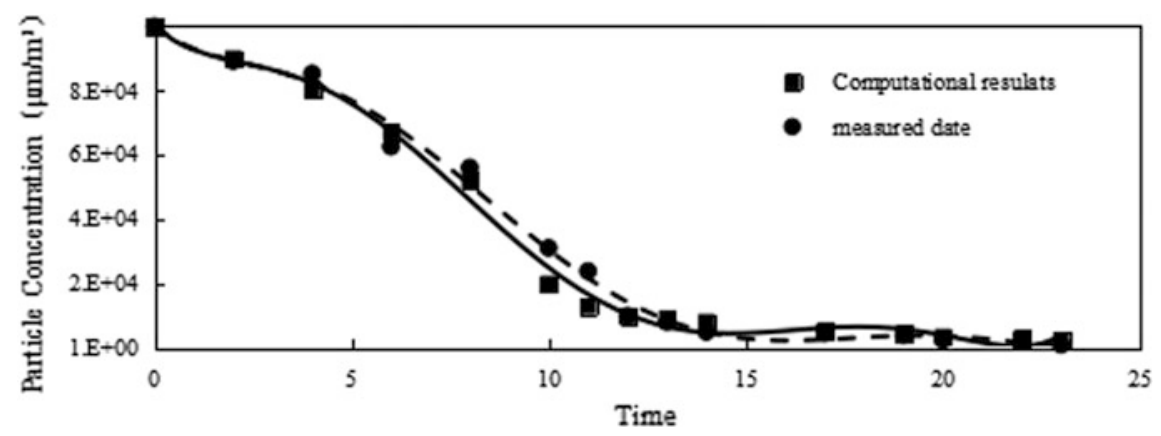

Fig. 2 Comparison of simulation and experimental data 
The average particle concentration comparison of the two zone- 1 regions is shown in Fig. 2. As can be seen from the figure, there is a high degree of consistency between the simulated data and the experimental data. Therefore, the DPM model can be applied for further research.

\section{Models and Boundaries}

\subsection{Introduction to the Model}

In this study, the prototype of the scale experiment of the literature [4] is used as the simulation object, and the ventilation shaft is added on the basis of the prototype. As shown in Fig. 3, the model is composed of tunnel, ventilation shaft and train. The specific geometric structure is: tunnel size $780 \mathrm{~m}$ (length) $\times 5 \mathrm{~m}$ (height) $4.2 \mathrm{~m}$ (width), ventilation shaft size $10 \mathrm{~m}$ (height) $\times 4 \mathrm{~m}$ (length) $\times 4.2 \mathrm{~m}$ (width), and train size $60 \mathrm{~m}$ (length) $\times 4.5 \mathrm{~m}$ (height) $\times 3.8 \mathrm{~m}$ (width). The air shaft is located in the middle of the tunnel, and the tail of the train stops 30 m away from the tunnel entrance at the initial time. The train accelerates to $12.7 \mathrm{~m} / \mathrm{s}$ $(60 \mathrm{~km} / \mathrm{h})$ with an acceleration of $1 \mathrm{~m} / \mathrm{s}^{2}$ and runs at a uniform speed for $28 \mathrm{~s}$.

\subsection{Force Analysis of Particles}

The discrete phase model uses the Lagrangian method to describe the particle trajectory. The trajectory of the particle can be expressed as:

$$
\frac{\mathrm{d} u_{\mathrm{p}}}{\mathrm{d} t}=F
$$

where $F$ is the force of particles. In this paper, the molecular forces that need to be considered in this case include: Saffman lift, drag force, gravity, and Brownian force.

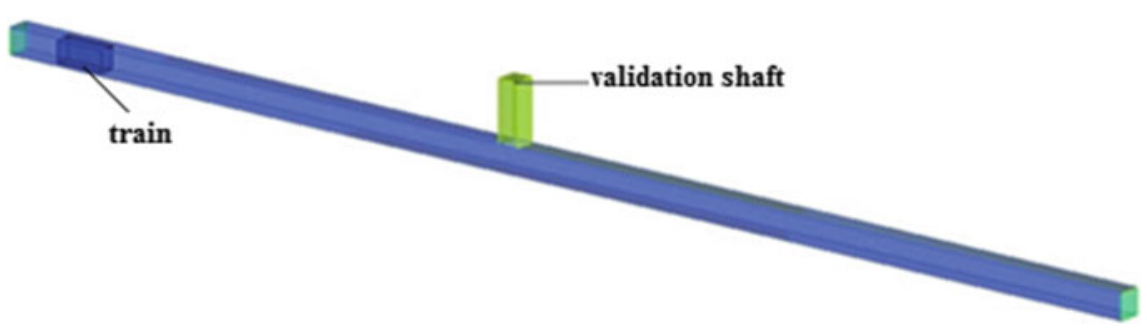

Fig. 3 Case model 
Table 1 Boundary condition settings

\begin{tabular}{l|l|l|l|l|l}
\hline Boundary & $\begin{array}{l}\text { Ventilation } \\
\text { shaft }\end{array}$ & $\begin{array}{l}\text { Tunnel } \\
\text { entrance }\end{array}$ & $\begin{array}{l}\text { Tunnel } \\
\text { exit }\end{array}$ & Tunnel wall & Tunnel ground \\
\hline $\begin{array}{l}\text { Condition } \\
\text { setting }\end{array}$ & $\begin{array}{l}\text { Pressure } \\
\text { outlet }\end{array}$ & $\begin{array}{l}\text { Pressure } \\
\text { inlet }\end{array}$ & $\begin{array}{l}\text { Pressure } \\
\text { outlet }\end{array}$ & $\begin{array}{l}\text { Collision and } \\
\text { reflection with } \\
\text { particles }\end{array}$ & $\begin{array}{l}\text { Collision } \\
\text { capture with } \\
\text { particulate } \\
\text { matter }\end{array}$ \\
\hline
\end{tabular}

\subsection{Boundary Conditions}

The particle source is a surface source, and the particle size distribution of the particle source adopts a double $R$ distribution. The minimum particle diameter is $1 \times 10^{-6} \mathrm{~m}$, the maximum particle diameter is $5 \times 10^{-6} \mathrm{~m}$, the average diameter is $3 \times 10^{-6} \mathrm{~m}$, the distribution index $n$ is 4 , and the number of diameters is 10 . When the train head moves to the position near the ventilation shaft, the particles are released. The particle release rate is $0.02 \mathrm{~kg} / \mathrm{s}$, and the initial particle velocity is $0.1 \mathrm{~m} / \mathrm{s}$ perpendicular to the downward direction of the ventilation shaft.

Boundary conditions are as follows Table 1.

\section{Results Analysis}

Figures 4 and 5 are distribution diagrams of airflow velocity and particle velocity in the ventilation shaft when the particle source is released for $1 \mathrm{~s}$, respectively. After the pollution source is released for $1 \mathrm{~s}$, the train runs directly below the ventilation shaft. Before the centerline of the ventilation shaft, vortexes appear near the tuyere, where the wind speed is smaller than that outside the vortexes, about $3.7 \mathrm{~m} / \mathrm{s}$. The diffusion velocity of particulate matter is also relatively small from the wall to the center of the ventilation shaft, which is basically below $2 \mathrm{~m} / \mathrm{s}$. The gravity effect of particulate matter has great influence here. Most of the particulate matter diffuses downward in the ventilation shaft, and the diffusion velocity is greater than the initial release velocity. After the central line of the ventilation shaft, the airflow in the ventilation shaft flows to the outside of the ventilation shaft. The wind speed near the area of the ventilation shaft is relatively high, which can reach $7 \mathrm{~m} / \mathrm{s}$. Particulate matter is affected by the coupling force of airflow directing to the outside of the ventilation shaft, which is much larger than the vertical downward gravity force. As a result, the release and diffusion direction of particulate matter from the source will change, and the particulate matter will diffuse to the outside of the ventilation shaft. It can be seen from the figure that the particle velocity in the release source region reaches about $10 \mathrm{~m} / \mathrm{s}$, and the direction is directed to the outside of the ventilation shaft. 


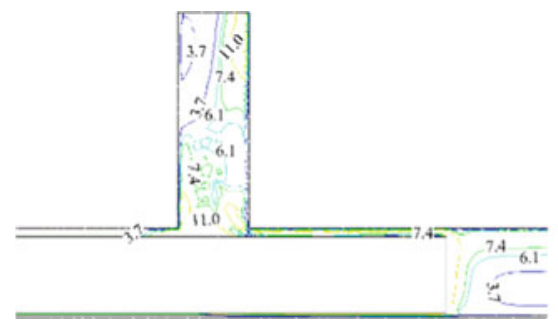

(A) Velocity contour map of central section in ventilation shaft area

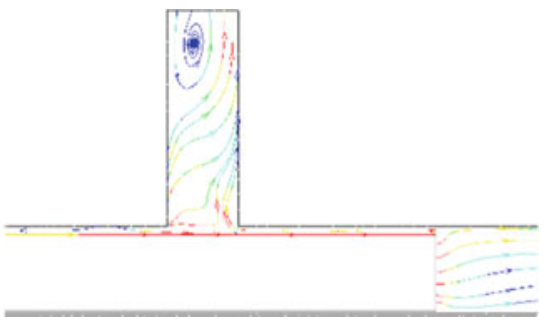

(B) Velocity vector map of central section in ventilation shaft area

Fig. 4 Airflow velocity diagram in the ventilation shaft for $1 \mathrm{~s}$

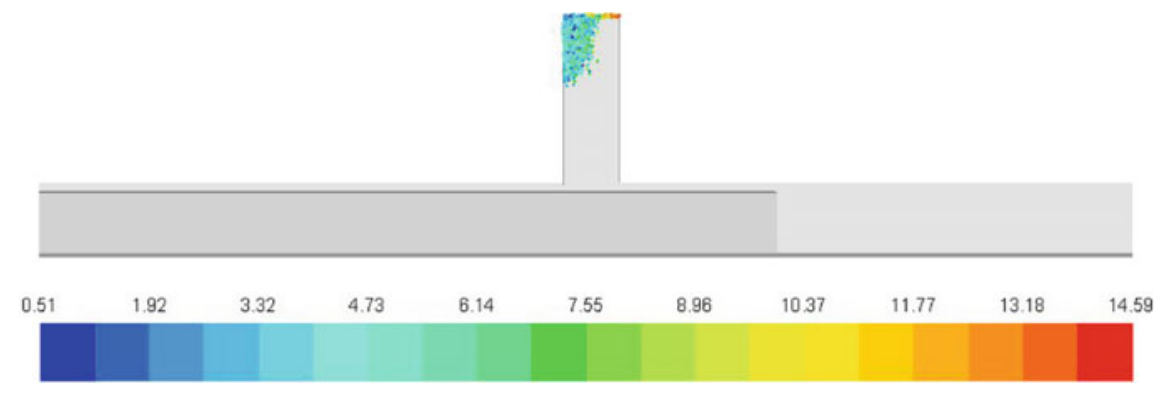

Fig. 5 Particle velocity distribution for $1 \mathrm{~s}$

Figures 6 and 7 are diagrams showing the distribution of airflow and particle velocity in the ventilation shaft when the particle source is released for $4 \mathrm{~s}$, respectively. At this point, the train starts to leave the ventilation shaft, and the tunnel is equivalent to a duct with T-shaped tee. Under the "piston action" of the train, the airflow flows through the upstream tunnel of the ventilation shaft and the ventilation shaft to the rear of the train. The airflow in the upstream tunnel of the ventilation shaft coincides with that in the confluence area. In the upstream area of the tunnel near the ventilation shaft, the wind speed is large, reaching above $8 \mathrm{~m} / \mathrm{s}$. For the ventilation shaft, the flow direction of the whole ventilation shaft is vertical to that of the confluence area, which results in the wind speed in the ventilation shaft section being lower than that in the tunnel. Further analysis shows that the vortex in the tunnel gradually moves down from the upper part of the ventilation shaft to the area below the middle of the ventilation shaft. The wind speed in the vortex zone is small, and the wind speed near the outside of the vortex zone is relatively large, basically above $3 \mathrm{~m} / \mathrm{s}$, which is greater than the wind speed of $1.8 \mathrm{~m} / \mathrm{s}$ near the shaft. Observing the velocity distribution map of particulate matter, we can find that the velocity distribution of particulate matter is very similar to that of the ventilation shaft. With the downward movement of the vortex area of the ventilation shaft, the particulate matter diffuses to the original vortex area and is 


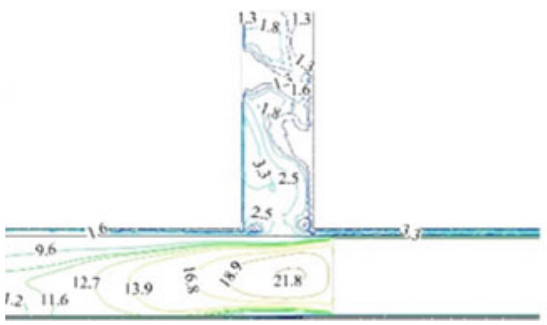

(A) Velocity contour map of central section in ventilation shaft area

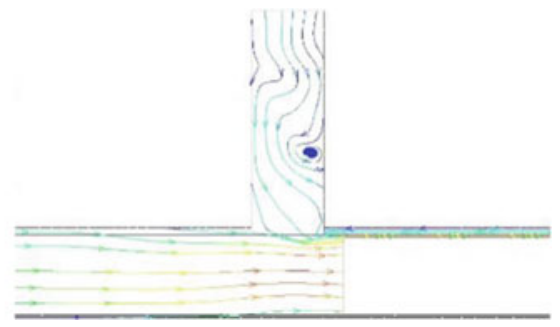

(B) Velocity vector map of central section in ventilation shaft area

Fig. 6 Airflow velocity diagram in the ventilation shaft for $4 \mathrm{~s}$

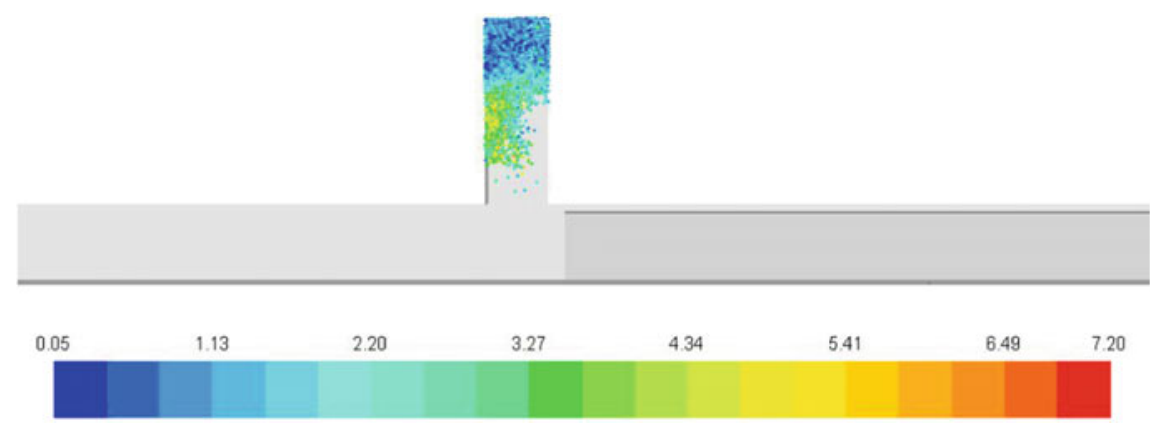

Fig. 7 Particle velocity distribution for $4 \mathrm{~s}$

relatively uniform in the area below the wind wellhead. Due to the small coupling force of the airflow and the short-acting time, the velocity of the particles is small, about $0.5 \mathrm{~m} / \mathrm{s}$. At the location of the vortex zone, the particles fail to diffuse into the zone, and there is substantially no particle distribution. In the outer region of the vortex zone, due to the accumulation of velocity in the first few seconds and the higher air coupling force in the zone, the particle diffusion rate is obviously higher than that in other regions, most of which are above $3 \mathrm{~m} / \mathrm{s}$.

Figures 8 and 9 are diagrams showing the distribution of airflow and particle velocity in the ventilation shaft when the particle source is released for $7 \mathrm{~s}$, respectively. When the particles are released for $7 \mathrm{~s}$, the train gradually leaves the ventilation shaft. At this time, the wind speed of the ventilation shaft becomes larger as the distance between the train and the ventilation shaft increases, and the wind speed in the upstream tunnel is opposite. Under the continuous diffusion of particulate matter, particulate matter has covered the whole ventilation shaft, and some particulate matter has diffused longitudinally in the interval tunnel. Before the release of particulate matter for $7 \mathrm{~s}$, there was no vortex zone with particulate distribution in the ventilation shaft area, which is also covered by particulate matter. Under the continuous action of air coupling and gravity, the diffusion rate of 


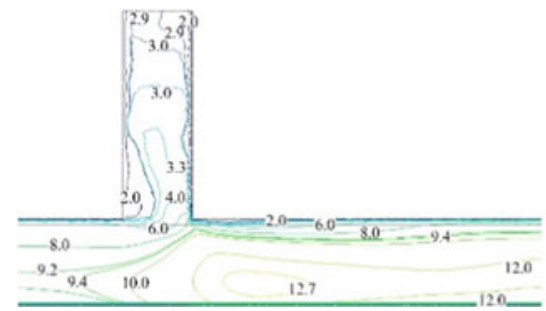

(A) Velocity contour map of central section in ventilation shaft area

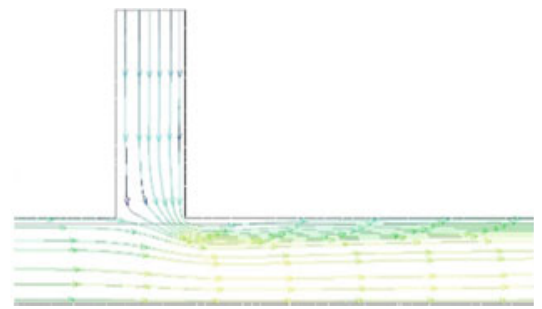

(B) Velocity vector map of central section in ventilation shaft area

Fig. 8 Airflow velocity diagram in the ventilation shaft for $7 \mathrm{~s}$

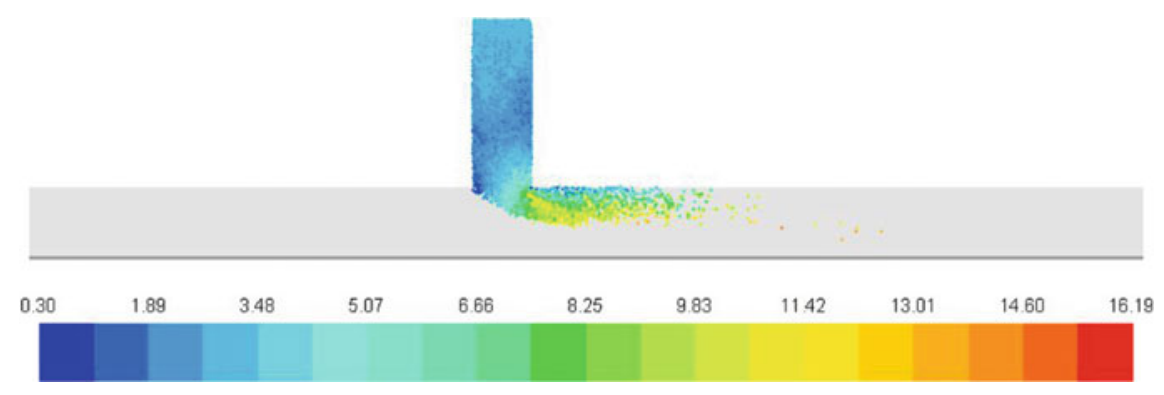

Fig. 9 Particle velocity distribution for $7 \mathrm{~s}$

particulate matter near the tuyere increases from about $0.5 \mathrm{~m} / \mathrm{s}$ at $4 \mathrm{~s}$ to about $2 \mathrm{~m} / \mathrm{s}$. Near the junction of the downstream tunnel and the ventilation shaft, there is a vortex near the upper wall of the tunnel. In the vortex region of the airflow, the diffusion rate of the particles is also significantly lower than other regions, and the diffusion velocity is about $2 \mathrm{~m} / \mathrm{s}$. In the outside of the vortex zone, the airflow speed reaches $8 \mathrm{~m} / \mathrm{s}$. The longitudinal force of airflow on particulate matter is obvious, which makes the particulate matter diffused in this area very fast, and can reach more than $8 \mathrm{~m} / \mathrm{s}$.

In summary, submicron particles have good airflow follow-up, and the change of airflow field in the tunnel has a great impact on particle diffusion.

\section{Conclusion}

In this study, CFD simulation method is used to simulate the diffusion of sudden pollutants in ventilation shaft of subway tunnel during train operation by combining dynamic grid and DPM model. Based on the analysis of pollutant diffusion in tunnels, the following conclusions can be drawn: 
(1) When the train runs in a subway tunnel, the airflow in the tunnel is greatly affected by the "piston effect." The direction of airflow in the ventilation shaft tuyere varies with the change of train position. According to the direction of the airflow, the airflow variation can be divided into two stages: the exhaust stage when the train is upstream or directly below the ventilation shaft, and the supply stage when the train is downstream.

(2) Submicron particles have good airflow followability, and their propagation and diffusion are greatly affected by airflow. Where the airflow velocity is high, the coupling force between particulate matter and air is large, and the diffusion velocity increases significantly. In the vortex region where the velocity of airflow is small, the coupling force between particulate matter and air is small, and the diffusion velocity is relatively small.

(3) Due to the influence of the tunnel airflow over time, the diffusion of submicron particles also changes with time. According to the diffusion direction and velocity of the particles in the tunnel, the diffusion of the particles can be divided into three stages:

Positive and negative diffusion of particulate matter in the ventilation shaft; positive diffusion of particulate matter in the ventilation shaft; and particulate matter diffuses longitudinally in interval tunnels.

\section{References}

1. Sextro, R., Lorenzetti, D., Sohn, M., et al.: Modeling the spread of anthrax in buildings. In: Indoor Air 2002, vol. 4, pp. 506-557 (2002)

2. Li, X., Yang, J., Sun, W.: Strategy to optimise building ventilation to aid rescue of hostages held by terrorists. Indoor Built Environ. 10(1), 39-50 (2005)

3. Hao, C., Weiding, L., Jinsheng, W., et al.: Airborne biochemical attacks and building environment security (1): a review. HV\&AC 35(1), 42-46 (2005)

4. Kim, J.Y., Kim, K.Y.: Experimental and numerical analyses of train-induced unsteady tunnel flow in subway. Tunnell. Undergr. Space Technol. Incorp. Trenchless Technol. Res. 22(2), 126-172 (2007)

5. Lu, W., Howarth, A.T., Adam, N., et al.: Modelling and measurement of airflow and aerosol particle distribution in a ventilated two-zone chamber. Build. Environ. 31(5), 417-423 (1996) 